\title{
Development of Inverse Mathematical Model of Rouse Formula to Estimate Suspended Sediment Concentration Along Width of Channel
}

\author{
Veero Mal Bheel ${ }^{1, *}$, Asif Ali Shaikh ${ }^{2}$, Ashfaque Ahmed Memon ${ }^{3}$, Sher \\ Khan Awan ${ }^{2}$ and Mashoque Ali Talpoor ${ }^{4}$ \\ 'Department of Basic Engineering, Sindh Agriculture University, Tando Jam, Sindh, \\ Pakistan \\ 2Department of Applied Mathematics, MUET, Jamshoro, Sindh, Pakistan \\ ${ }^{3}$ Department of Civil Engineering, MUET, Jamshoro, Sindh, Pakistan \\ ${ }^{4}$ Department of Irrigation and Drainage, SAU, Tando Jam, Sindh, Pakistan
}

Article Type: Article

Article Citation: Veero Mal Bheel, Asif Ali Shaikh, Ashfaque Ahmed Memon, Sher Khan Awan, Mashoque Ali Talpoor. Development of inverse mathematical model of Rouse formula to estimate suspended sediment concentration along width of channel. Indian Journal of Science and Technology. 2020; 13(04), 460-474. DOl: 10.17485/ijst/2020/ v013i04/149629

Received date: December 13, 2019

Accepted date: January 16, 2020

*Author for correspondence: Veero Mal Bheel Vveeromal@ sau.edu.pk 9 Department of Basic Engineering, Sindh Agriculture University, Tando Jam, Sindh, Pakistan

\section{Abstract}

Background/objective: The sedimentation is a burning issue all around the world; hence this research will help the irrigation engineers to solve the sedimentation problems related to irrigation channels, hydraulic structures as well as in the field of agriculture. In this present research study, the inverse mathematical model of Rouse formula is developed to calculate the suspended sediment concentration along the width of an open channel. Methodology/analysis: For derivation of the model, a well-known differential advection-diffusion equation is solved analytically with respect to $x$-axis along the width of channel. The model is also validated and checked with experimental results and calculated results by the newly developed model. Findings: A mathematical model has been developed for suspended sediment concentration along the width of channel. Furthermore, this model applied and compared with experimental results and observations which were conducted in open channel. Finally, for more validation and reliability of a newly developed model, the average maximum and minimum percentage errors are computed. These errors indicate that the proposed model has the best accuracy and resemblance when percentage errors of the newly developed model are computed. Application: A newly developed model can be applied to estimate suspended sediments concentration from open channels. This model is also useful for irrigation engineers to find out suspended sediments concentration profiles along the horizontal direction from the centre to channel banks at the mid-depth of water.

Keywords: Advection-Diffusion Equation, Rouse Number, Mass Diffusivity, Suspended Sediment Concentration, Irrigation Channels. 


\section{Introduction}

The sediment transportation in open channels such as irrigation canals is divided into two main parts, viz. (i) suspended load and (ii) bed load. The suspended load consists of fine sediments that remain in suspension in the water column due to eddy turbulence whereas bed load is the composition of coarser particles which transport over the bed by saltation, sliding, and rolling. The transport of suspended sediment in open channels has an enormous impact on real-life situations in terms of engineering applications and water quality. Therefore, for a longtime, sediment transport has remained an issue all around the world in terms of the reduction of quality and quantity of water. So sediment plays a key role in elemental cycling in an aquatic environment. They are the main source for transporting a specific amount of particles and contaminants which leave a bad impact on human life. Water consumers of tail reach with a large number of contaminants are compelled to remove this contaminant from water or may face a shortage of reservoirs storage because of siltation. As a result, reservoir sedimentation usually becomes large compared to that expected at the design stage. To manage large reservoirs, this situation necessitates observing sediment transport from the catchment to the reservoir and its deposition in the reservoir [1]. Furthermore, slow and continue the enrichment of reservoir water with nutrients leads to an increase in production and sedimentation of organic material.

The source of bed load is suspended sediments that remain in suspension with water flow for a specific time before settling down on the bed. The quantity of suspended sediment in the river directly influences different design and operation aspects of hydraulic structures like ecosystem, biodiversity, fluvial geomorphology, etc. Owing to this, it is very important to calculate the precise volume of suspended sediments in river flow for the proper index to evaluate potential circumstances to manage water resources. Different attempts have been made for prediction of suspended sediment in rivers but because of its multifaceted mechanism and extremely nonlinear endeavors of parameters, these attempts are unable to predict the exact volume of sediments [2].

In open channel flow, the higher suspended sediment is observed due to more flow rate of water, or steep bed slope, or due to combined effect of both parameters. In laboratory experimentations, the severe transport condition may be additional yield by using lightweight particles [3-4]. The sediment volume flowing with water is obtained from data collected with adequate frequency to get dependable estimations for computational intervals. Usually, sediment discharge statistics are calculated on daily or annual bases depending on the observed data, though sometimes part of the record is based on discrete or seasonal intervals also. Subject to type and incidence of existing data, the proper method is adopted to compute sediment discharge [5]. The problems that take place due to excess suspended sediment in open channels have pronounced significance in the field of hydraulics and agricultural engineering. The most significant problem caused due to excess sediment during flood seasons is rising of river bed level and consequently the water level because of deposition. At the upper sections, the bed slope is steep, velocity is high henceforth rivers take a heavy amount of sediment during the floods [6].

Some existing modifications and models are reviewed for new development of the model. In 2017, seven mathematical models were reviewed including fractional 
Advection-Diffusion Equation (fADE) model and an innovative method for vertical distribution of concentration of suspended sediment was derived. Their approach correlates sensitivity of fractional index of fADE model with size and settling velocity of sediment particles [7]. In 2018, a method was derived appropriate expression for depth-averaged $\beta$; modified the expression of sediment and turbulent diffusion coefficient and also establish the relation between $\beta$ and normalized settling velocity for finding suspended sediment concentration by selecting sediment diffusion coefficient on based of finite mixing length theory through turbulent mixing process [8] a 2-D numerical model for vertical distribution of concentration of suspended sediment from channel bed to water surface [9]. Zhou developed the model for the exponent of the reduction of the setting velocity by applying the probability method based on the Tsallis entropy theory. Deprived formula is a function of volumetric suspended concentration, the relative mass density, and Reynolds number of particles [10]. In the view of these facts and figures, this research and study is conducted for suspended sediment concentration along the width of the channel from the center of width and mid-depth of flow towards the banks of the channel.

So far many researchers have developed and modified mathematical models for computation of vertical suspended sediment profile in open channels flow. The main focus of this research is to develop new inverse mathematical model of Rouse Formula for suspended sediment concentration using advection diffusion equation. This model will be useful for irrigation engineers to find out suspended sediments concentration profile along width of channel from centre to channel banks at the mid-depth of water.

\section{Research Methodology}

In the previous research, Rouse formula was developed to calculate suspended sediment load in a vertical column of flow with reference to channel bed. In this method, the vertical concentration profile from the bed of the channel towards the water surface is plotted. The Rouse formula was derived by solving advection diffusion equation w.r.t " $y$ " It was given as

$$
\frac{C}{C_{\mathrm{a}}}=\left(\frac{D-y}{y} \cdot \frac{a}{D-a}\right)^{R}
$$

where $R=C=$ Unknown concentration at any distance ' $y$ ' at a vertical column of flow. $C_{\mathrm{a}}=$ Known concentration at height 'a' above bed at reference level, $D=$ Depth of flow, $R=$ Rouse number, $\mathrm{K}=$ Von Karman's universal constant $=0.4, \omega=$ Settling Velocity, and $=$ Shear Velocity

\subsection{Proposed Newly Developed Mathematical Model}

\subsubsection{Derivation of Model}

The inverse mathematical model of Rouse formula has been developed to calculate suspended sediment load inflow along the width of the channel with reference to the center of channel width at the mid-depth of flow toward banks. The differential 
advection-diffusion equation is solved analytically to develop a new mathematical model w.r.t "x."

$$
\epsilon_{s} \frac{d C}{d x}+\omega c=0
$$

where $\epsilon_{s}$ is sediment diffusion coefficient, $C$ is volumetric sediment concentration, $x$ is horizontal length along the width of the channel, $\omega$ is settling velocity of the suspended particle.

Equation (2) has been solved analytically applying all possible and available methods that are used for solving an ordinary differential equation. To derive an inverse mathematical model, in steady flow, the upward diffusion of sediments is equal to the settling flux of particles as given by equation (2).

Where $C=$ suspended sediment concentration by weight along width from center toward banks of the channel.

$\omega=$ Settling Velocity of particle

$\epsilon_{\mathrm{s}}=$ Mass diffusivity coefficient, generally function of " $x$ "

At any point on the width of the channel, shear stress is

$$
\tau_{x}=\tau_{0}\left(\frac{w-x}{w}\right)
$$

Shear stress perpendicular to fluid flow toward the banks of the channel is

$$
\tau_{x}=\epsilon_{m} \rho \frac{d u}{d x}
$$

where $\epsilon_{m}$ is the diffusion coefficient for momentum distribution. From equation (4), negative sign shows that flow velocity is decreasing toward the banks of the channel.

The logarithmic form of velocity along the width of the channel and perpendicular to fluid flow.

$$
\frac{d u}{d x}=\frac{U_{*}}{K x}
$$

where " $K$ " is Von Karman universal constant and its value is 0.4 .

Assuming $\in_{s=} \in_{m}$ and using Equations (3)-(5), yield

$$
\tau_{0}\left(\frac{w-x}{w}\right)=-\epsilon_{s} \rho \frac{d u}{d x}
$$

Putting in equation (6)

$$
\tau_{0}\left(\frac{w-x}{w}\right)=-\epsilon_{s} \rho \frac{U_{*}}{K x}
$$


As we know that

$$
U_{*}=\sqrt{\frac{\tau_{0}}{\rho}}
$$

Squaring on both side

$$
\tau_{0}=\rho U_{*}^{2}
$$

Putting the value of in equation (7), we get

$$
\epsilon_{s=}-U_{\star} k x\left(\frac{w-x}{w}\right)
$$

Again putting equation (8) in equation (2), yields

$$
\frac{d C}{C}=\frac{R}{x}\left(\frac{w}{w-x}\right) \therefore R=\frac{\omega}{K U_{*}}
$$

Integrating both sides from a to using partial fraction we get

$$
\int_{a}^{x} \frac{d C}{C}=w R \int_{a}^{x}\left(\frac{A}{x}+\frac{B}{w(w-x)}\right) d x
$$

If $x=w=>B=\frac{1}{w}$ and If $x=0$ then $A=\frac{1}{w}$

Putting the value of $A$ and $B$ in equation (9)

$$
\int_{a}^{x} \frac{d C}{C}=w R \int_{a}^{x}\left(\frac{1}{w x}+\frac{1}{w(w-x)}\right) d x
$$

From equation (10), we have

$$
\frac{C_{x}}{C_{a}}=\left(\frac{x}{(w-x)} \cdot \frac{(w-a)}{a}\right)^{R}
$$

It is the required solution of equation (2) and equation (11) is a newly developed mathematical model for suspended sediments concentration along the width of channel from centre of width to channel banks at mid-depth of flow.

\section{Results and Discussion}

In this research, a mathematical model has been derived by solving the advectiondiffusion equation analytically for suspended sediment concentration along the width of 
the channel. This model is applied to find out the suspended sediments concentration with the help of experimental data. From Tables 1-5, the values of " $C_{\mathrm{x}}$ " are generated by the newly developed formula and the values " $C_{a}$ " is known concentration which was taken at centre of width and mid-depth of Rahuki channel which is located near Hyderabad city. The range of Rouse number for bed load, suspended load, and wash load was calculated by Pekker Leonid on basis of Shields diagram [11]. Rouse number is decreasing towards the centre of channel and increasing towards the banks of the channel because Rouse number is directly proportional to the settling velocity of particles and inversely proportional to shear velocity. The settling velocity is also decreasing towards the centre of channel due to increasing the flow velocity. As flow velocity increase toward the centre of the channel, the settling velocity decreases simultaneously. To check the validity and reliability of newly developed, the theoretical computed results are compared to experimental observations. This shows that the calculated suspended sediment concentration by a newly developed model has the best agreement and accuracy with the observed suspended sediments concentration collected at different RDs comprising cross-section elements of the Rahuki channel. The trend of suspended sediments profile is in the parabolic shape as shown in Figures 1-5. Finally, on the basis of findings this indicates that the newly developed mathematical model have the significant results and the best accuracy with experimental and observed results at different RDs. For further more validation and justification, average maximum and minimum percentage errors have been computed as shown in Table 6. The average maximum and minimum percentage errors are found out $6.596 \%$ and $0.8002 \%$ respectively.

\subsection{Computation of Suspended Sediment Concentration at 0 RD}

Using the newly developed formula, computations are made to determine suspended sediment concentration at $0 \mathrm{RD}$. These values are compared with the actual (observed) values of suspended sediment concentration and percentage error between the two values is calculated, as shown in Table 1.

From the values as shown in Table 1, sediment concentration calculated by the newly developed formula is compared with the actual (observed) suspended sediment concentration at $0 \mathrm{RD}$, graphically, as shown in the following figure.

\subsection{Computation of Suspended Sediment Concentration at 8 RD}

Using the newly developed formula, computations are made to determine suspended sediment concentration at $8 \mathrm{RD}$. These values are compared with the actual (observed) values of suspended sediment concentration and percentage error between the two values is calculated, as shown in Table 2.

From the values as shown in Table 2, sediment concentration calculated by the newly developed formula is compared with the actual (observed) suspended sediment concentration at $8 \mathrm{RD}$, graphically, as shown in the following figure. 


\subsection{Computation of Suspended Sediment Concentration at 16 RD}

Using the newly developed formula, computations are made to determine suspended sediment concentration at $16 \mathrm{RD}$. These values are compared with the actual (observed) values of suspended sediment concentration and percentage error between the two values is calculated, as shown in Table 3.

From the values as shown in Table 3, sediment concentration calculated by the newly developed formula is compared with the actual (observed) suspended sediment concentration at $16 \mathrm{RD}$, graphically, as shown in the following figure.

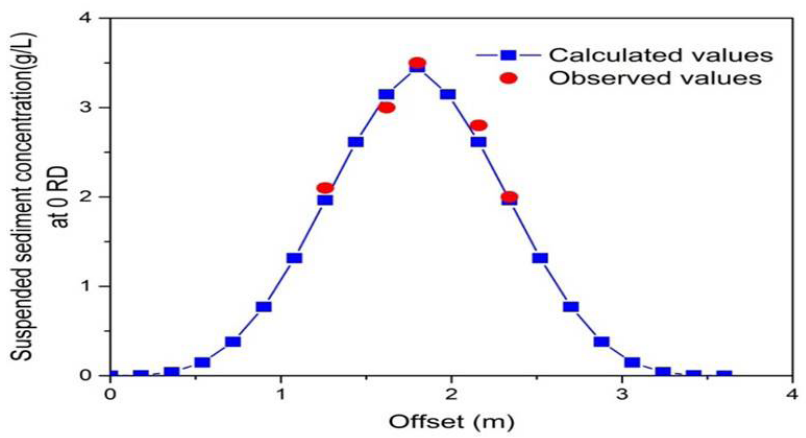

FIGURE 1. Graphical comparison of calculated and observed suspended sediment concentration at $0 \mathrm{RD}$.

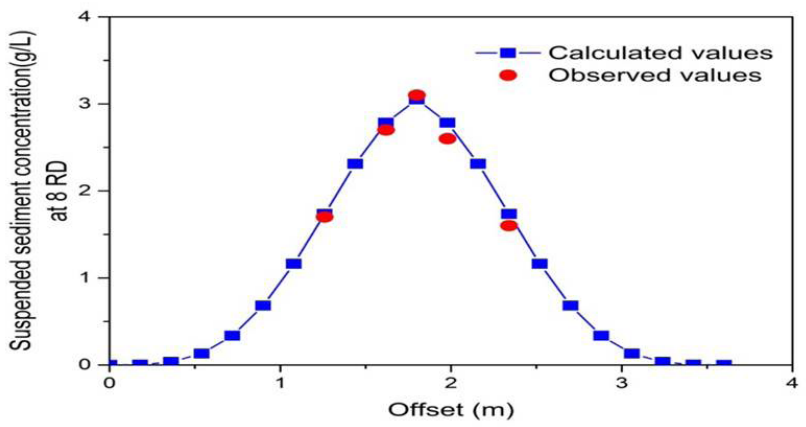

FIGURE 2. Graphical comparison of calculated and observed suspended sediment concentration at 8 RD.

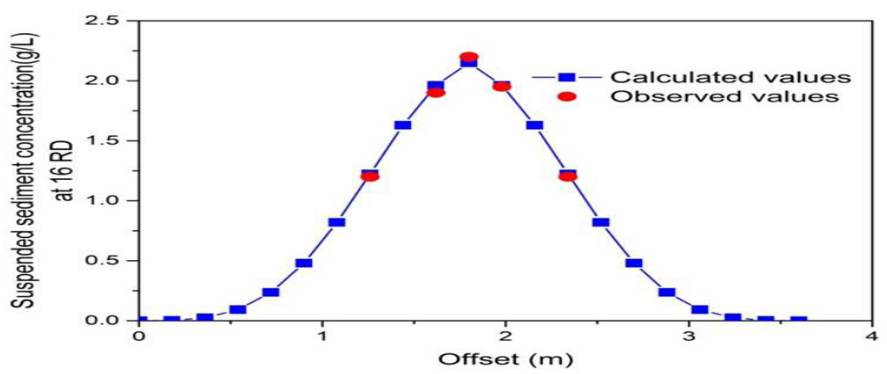

FIGURE 3. Graphical comparison of calculated and observed suspended sediment concentration at $16 \mathrm{RD}$. 


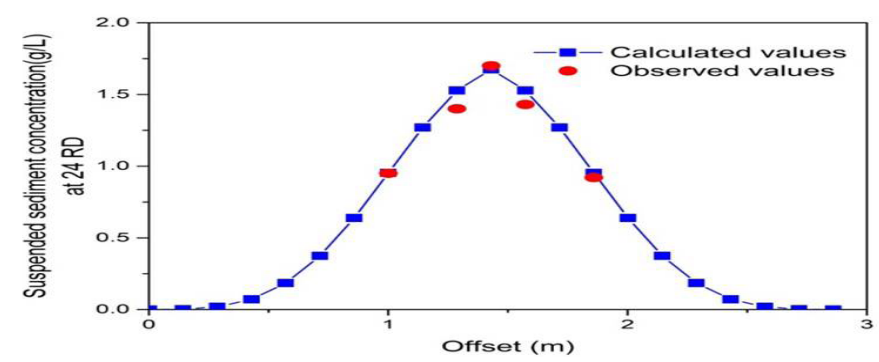

FIGURE 4. Graphical comparison of calculated and observed suspended sediment concentration at $24 \mathrm{RD}$.

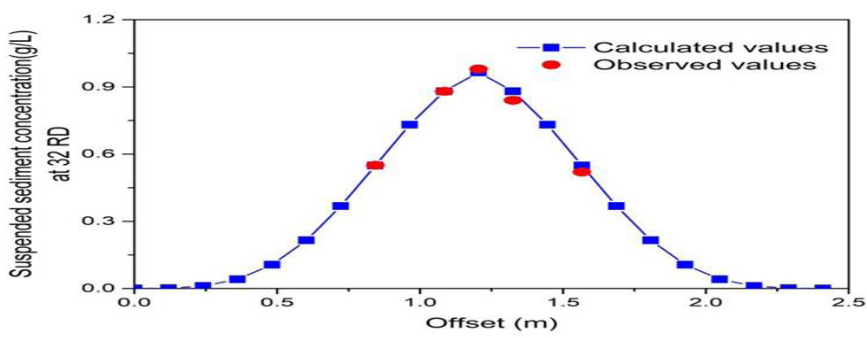

FIGURE 5. Graphical comparison of calculated and observed suspended sediment concentration at $32 \mathrm{RD}$.

\subsection{Computation of Suspended Sediment Concentration at 24 RD}

Using the newly developed formula, computations are made to determine suspended sediment concentration at $24 \mathrm{RD}$. These values are compared with the actual (observed) values of suspended sediment concentration and percentage errors between the two values are calculated, as shown in Table 4.

From the values as shown in Table 4, sediment concentration calculated by the newly developed formula is compared with the actual (observed) suspended sediment concentration at $24 \mathrm{RD}$, graphically, as shown in the following figure.

\subsection{Computation of Suspended Sediment Concentration at 32 RD}

Using the newly developed formula, computations are made to determine suspended sediment concentration at $32 \mathrm{RD}$. These values are compared with the actual (observed) values of suspended sediment concentration and percentage error between the two values is calculated, as shown in Table 5.

From the values as shown in Table 5, sediment concentration calculated by the newly developed formula is compared with the actual (observed) suspended sediment concentration at $32 \mathrm{RD}$, graphically, as shown in the following figure. 


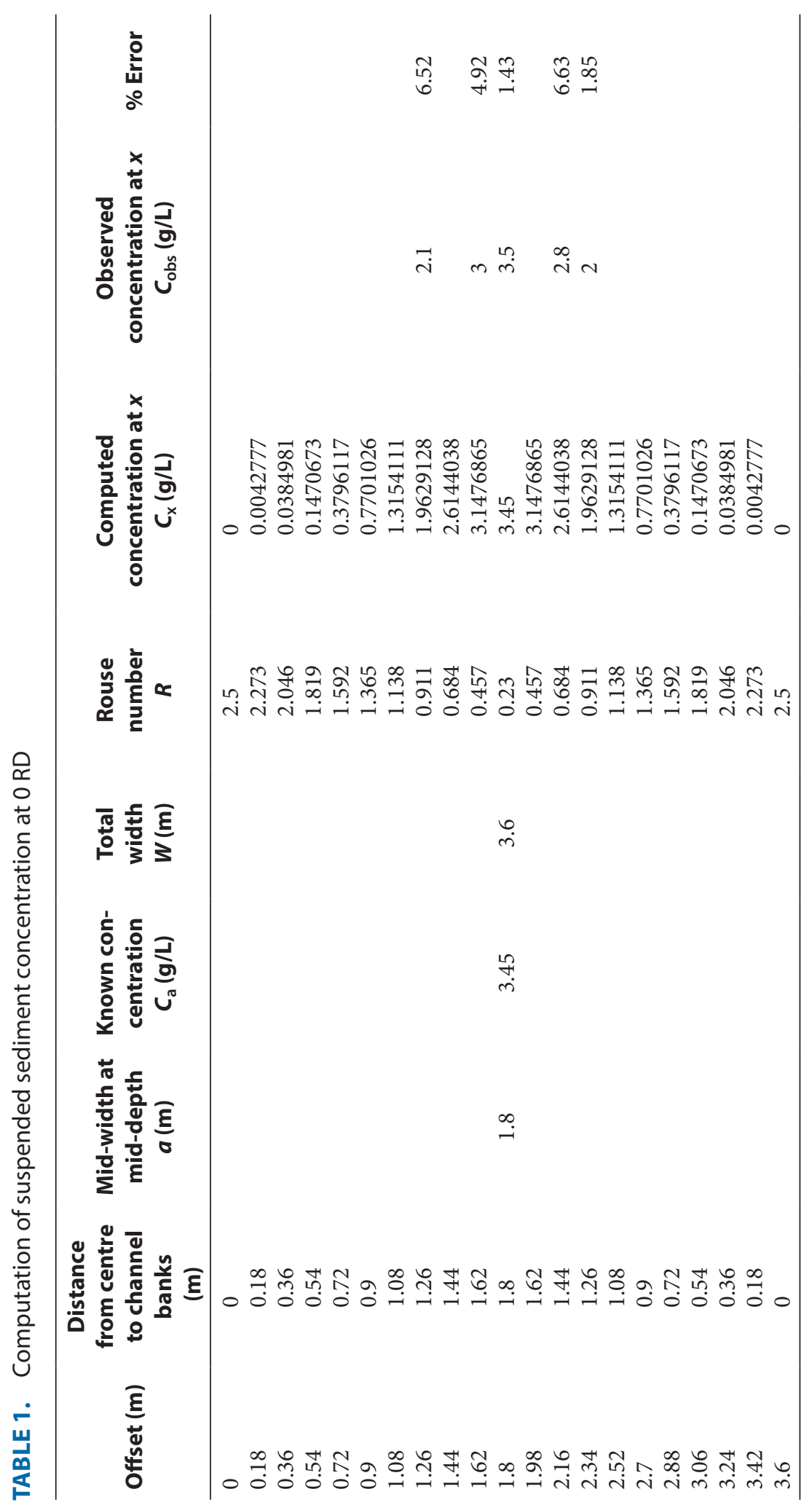




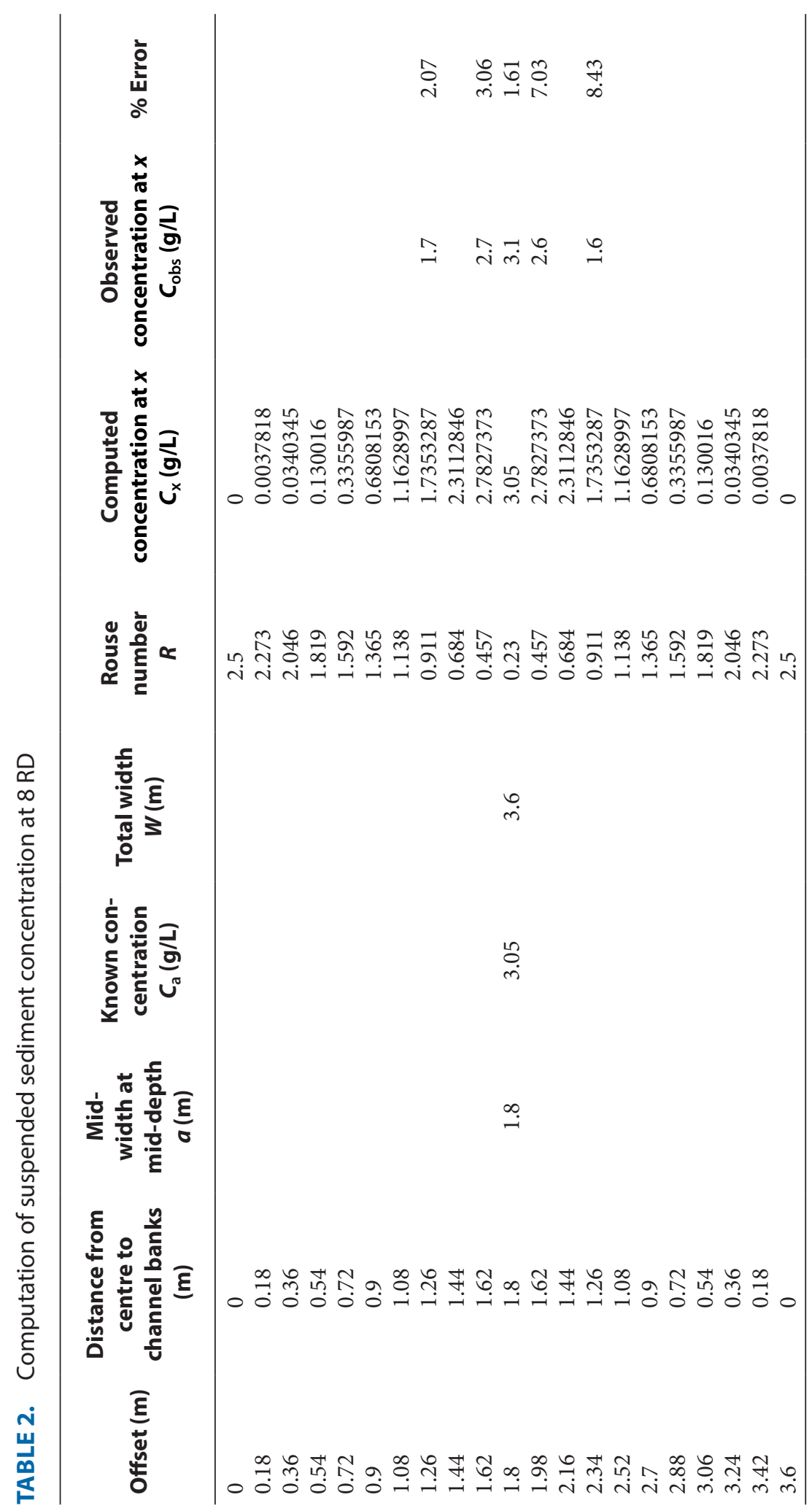




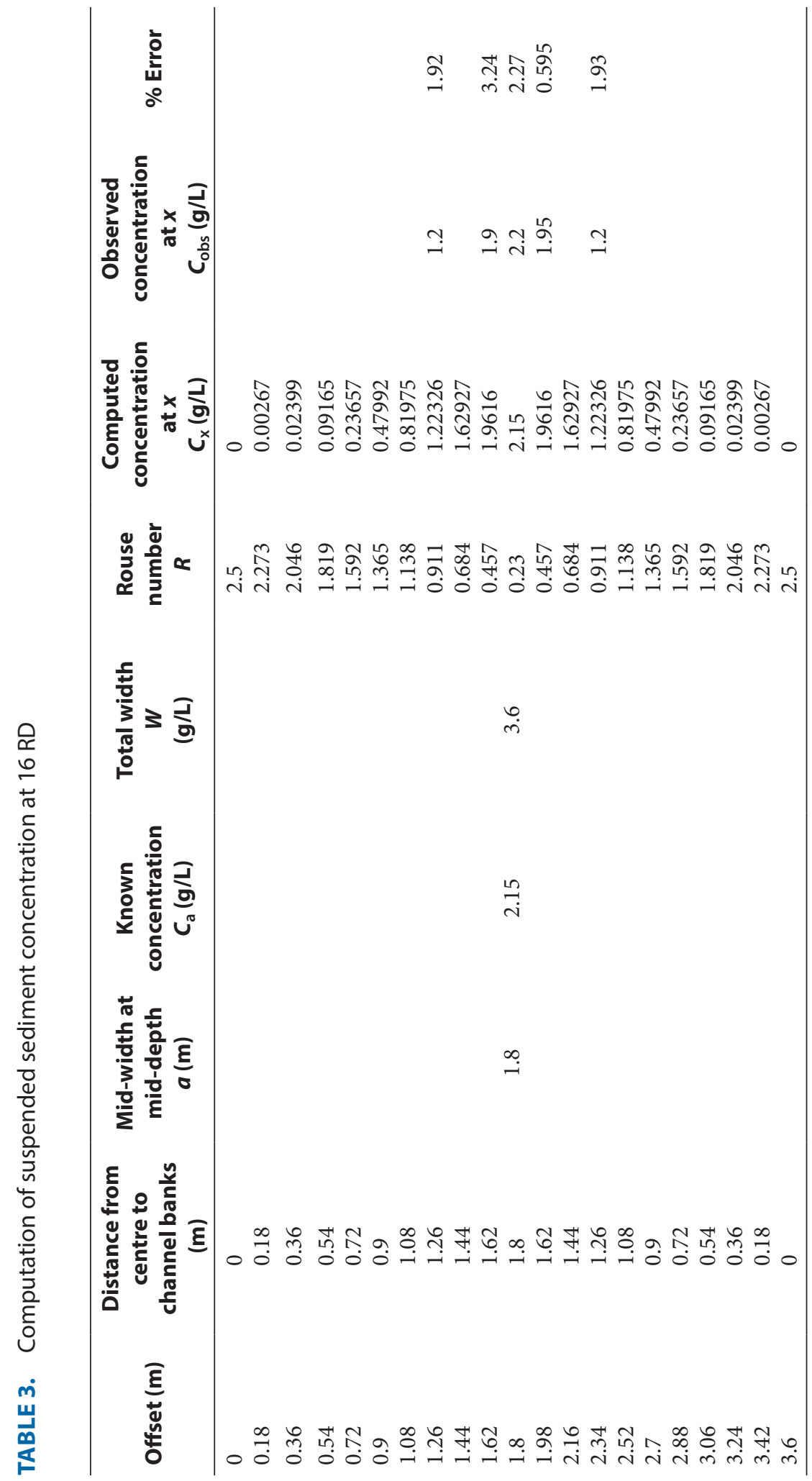




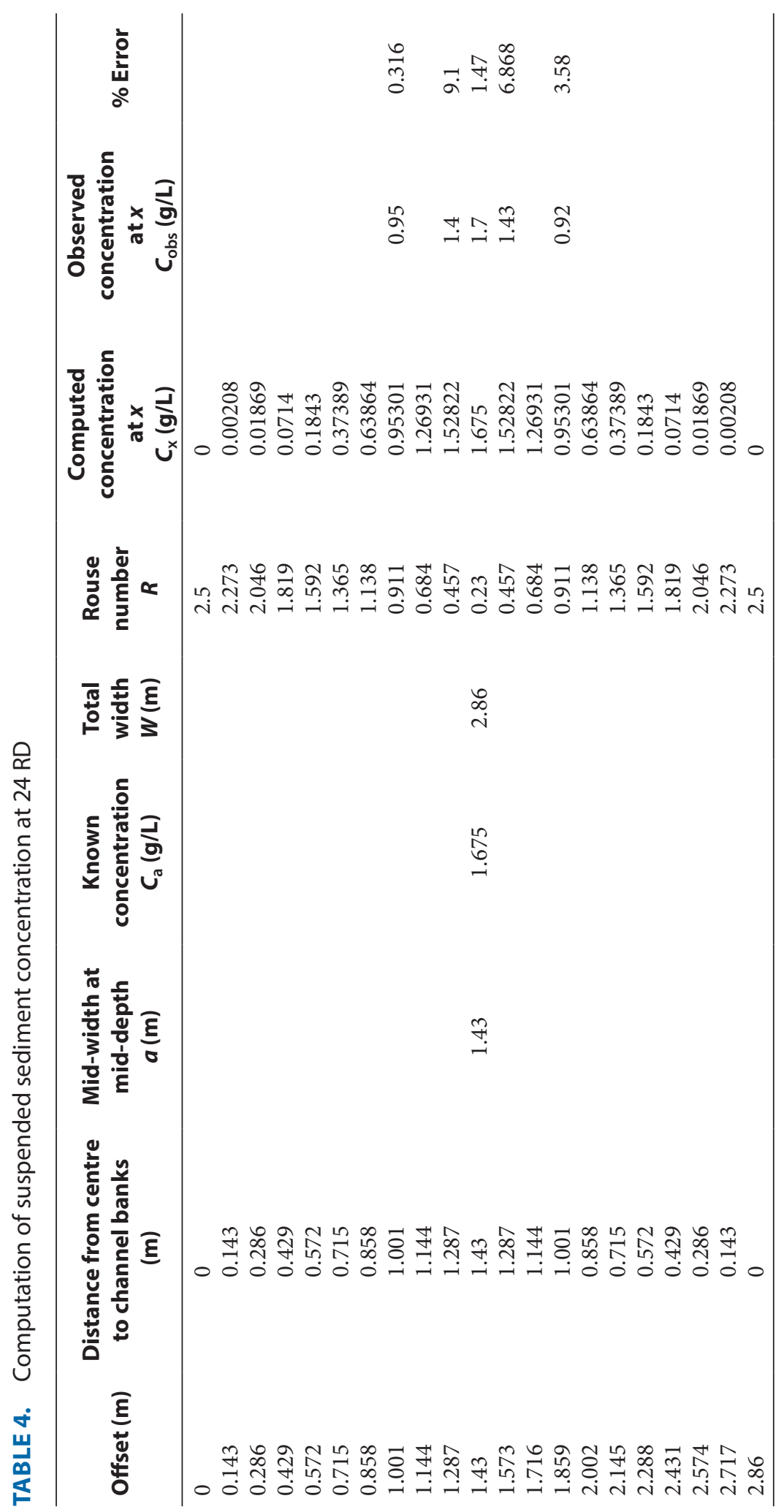




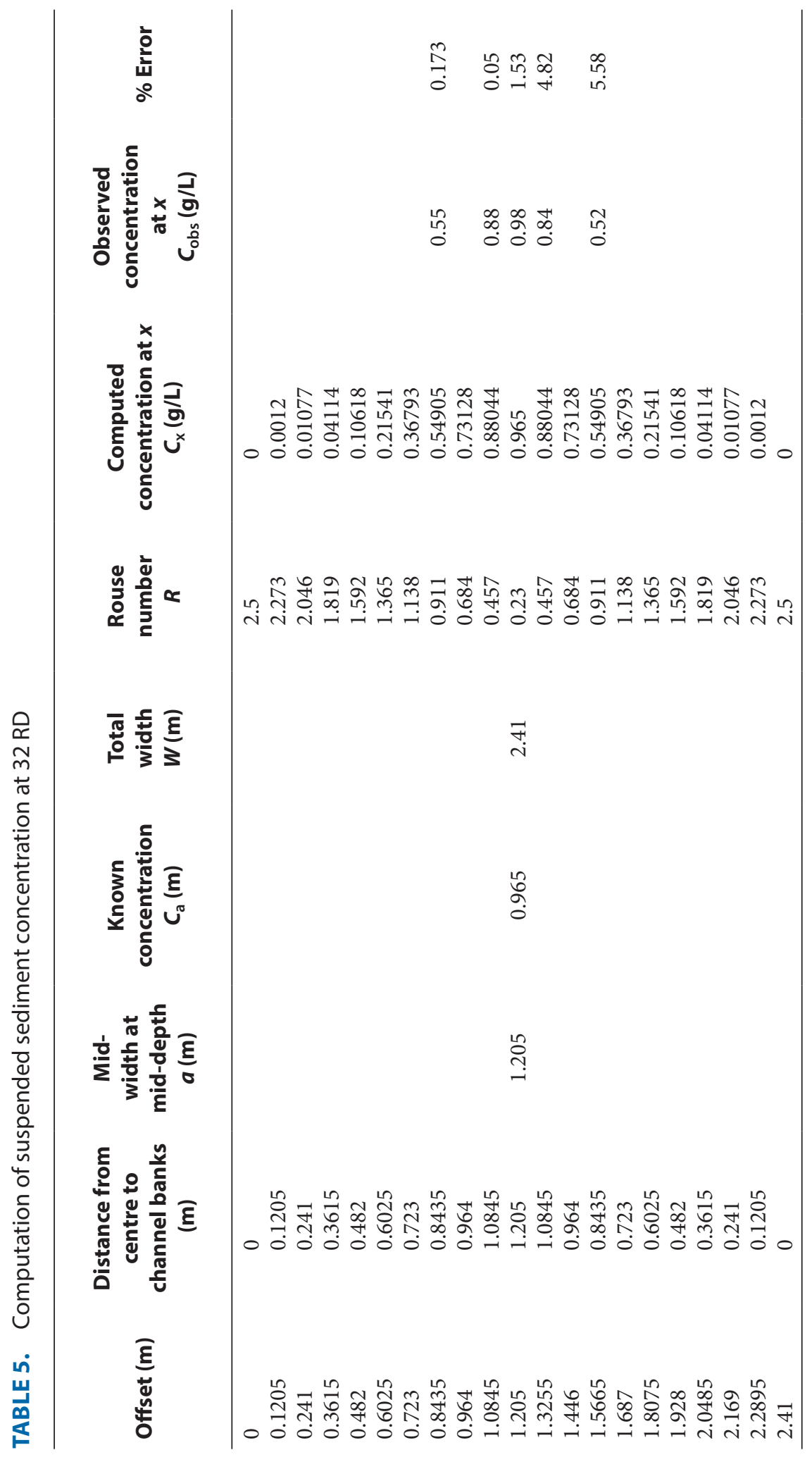


TABLE 6. Average maximum and minimum percentage errors at different RDs

\begin{tabular}{llllllc}
\hline RD & 0 RD & 8 RD & 16 RD & 24 RD & 32 RD & Average \% error \\
\hline Max: \% error & 6.63 & 8.43 & 3.24 & 9.1 & 5.58 & 6.596 \\
Min: \% error & 1.43 & 1.61 & 0.595 & 0.316 & 0.05 & 0.8002 \\
\hline
\end{tabular}

\section{Conclusion}

In the current research and study, a new mathematical model has been developed by solving a differential advection-diffusion equation analytically and the developed model has been also applied to estimate suspended sediments concentration at different RDs on the bases of observed data. In the next step, the computed results are also compared with experimental observations and results. It is observed that calculated results have the best accuracy and significance with experimental results. The trend of suspended sediments concentration is in parabolic shape at different RDs of channel. Suspended sediments concentration is increasing towards the centre and decreasing towards the banks of channel. Furthermore, for the validation and accuracy of the model, the average maximum and minimum percentage errors were computed and the result comes out $6.596 \%$ and $0.8002 \%$. This model is useful and applicable for irrigation engineers to estimate suspended sediments concentration along the width of the channel from at mid-width and depth of flow towards the channel banks.

\section{References}

1. Bertram J, Balance R. A practical guide to the design and implementation of freshwater quality studies and monitoring programmes. Published on behalf of the United Nations Environmental Programme (UNEP) and World Health Organization (WHO), E \& FN Spon Publishers. 1996; 172-177. https://apps.who.int/iris/handle/10665/41851

2. Lafdani E, Kakaei A, Moghaddam Nia, Ahmadi A. Daily suspended sediment load prediction using artificial neural networks and support vector machines. Jornal of Hydrology. 2013; 478, 50-62. DOI: 10.1016/j.jhydrol.2012.11.048.

3. Armanini A, Capart H, Fraccarollo L, Larcher M. Rheological stratification in experimental free-surface flows of granular-liquid mixtures. Journal of Fluid Mechanics. 2005; 532, 269-319. https://doi.org/10.1017/S0022112005004283

4. Capart H, Fraccarollo L. Transport layer structure in intense bed-load. Geophysical Research Letters. 2011; 38(20), 1-6. https://doi.org/10.1029/2011GL049408

5. Revil-Baudard T, Chauchat J, Hurther D, Barraud PA. Investigation of sheet-flow processes based on novel acoustic high-resolution velocity and concentration measurements. Journal of Fluid Mechanics. 2015; 767, 1-30. DOI: 10.1017/jfm.2015.145.

6. Omran HA, Fattah MY, Sulaiman SE. A model for removing sediments from open channels. Journal of Kerala University. 2015; 13(1), 22-35. DOI: 10.5897/IJPS2013.4074.

7. Nie S, Sun H, Zhang Y, Chen D, Chen W, Chen L, Schaefer S. Vertical distribution of suspended sediment under steady flow: existing theories and fractional derivative model. Discrete Dynamics in Nature and Society. 2017; 1-11. https://doi.org/10.1155/2017/5481531 
8. Jain P, Kumbhakar M, Ghoshal K. A mathematical model on depth-averaged $\beta$-factors in an open-channel turbulent flow. Environmental Earth Sciences. 2018; 77(6), 253. https://link. springer.com/article/10.1007/s12665-018-7428-0

9. Zhang JX, Liu H. A vertical 2-D numerical simulation of suspended sediment transport. Journal of Hydrodynamics. 2007; 19(2), 217-224. https://doi.org/10.1016/S1001-6058(07)60051-1

10. Zhu Z, Wang H, Peng D, Dou J. Modelling the hindered settling velocity of a falling particle in a particle-fluid mixture by the Tsallis entropy theory. Entropy. 2019; 21(1), 55. DOI: 10.3390/ e21010055.

11. Leonid P. A calculator for sediment transport in micro channels based on the Rouse number. arXiv preprint arXiv. 2017; 1-10. https://arxiv.org/abs/1712.07073 